\title{
A Comparative CFD Study on Simulating Flameless Oxy-Fuel Combustion in a Pilot-Scale Furnace
}

\author{
Mersedeh Ghadamgahi, ${ }^{1,2}$ Patrik Ölund, ${ }^{1}$ Tomas Ekman, ${ }^{3}$ \\ Nils Andersson, ${ }^{2}$ and Pär Jönsson ${ }^{2}$ \\ ${ }^{1}$ Ovako Sweden AB, Hofors, Sweden \\ ${ }^{2}$ Department of Materials Science and Engineering, KTH Royal Institute of Technology, Stockholm, Sweden \\ ${ }^{3} A G A$ AB, The Linde Group, Stockholm, Sweden
}

Correspondence should be addressed to Mersedeh Ghadamgahi; mersedeh@kth.se

Received 3 June 2016; Revised 17 August 2016; Accepted 19 September 2016

Academic Editor: Richard Saurel

Copyright (C) 2016 Mersedeh Ghadamgahi et al. This is an open access article distributed under the Creative Commons Attribution License, which permits unrestricted use, distribution, and reproduction in any medium, provided the original work is properly cited.

\begin{abstract}
The current study presents a method to model the flameless oxy-fuel system, with a comparative approach, as well as validation of the predictions. The validation has been done by comparing the predicted results with previously published experimental results from a $200 \mathrm{~kW}$ pilot furnace. A suction pyrometer has been used to measure the local temperature and concentrations of $\mathrm{CO}, \mathrm{CO}_{2}$, and $\mathrm{O}_{2}$ at 24 different locations. A three-dimensional CFD model was developed and the validity of using different submodels describing turbulence and chemical reactions was evaluated. The standard $k-\varepsilon$ model was compared with the realizable $k-\varepsilon$ model for turbulence, while Probability Density Function (PDF) with either chemical equilibrium or the Steady Laminar Flamelet Model (SLFM) was evaluated for combustion. Radiation was described using a Discrete Ordinates Model (DOM) with weighted-sumof-grey-gases model (WSGGM). The smallest deviation between predictions and experiments for temperature (1.2\%) was found using the realizable $k-\varepsilon$ model and the SLFM. This improvement affects the prediction of gaseous species as well since the deviation between predictions and experiments for $\mathrm{CO}_{2}$ volume percentages decreased from $6 \%$ to $1.5 \%$. This provides a recommendation for model selections in further studies on flameless oxy-fuel combustion.
\end{abstract}

\section{Introduction}

As the challenges of industrial pollution and energy consumption grow into one of the biggest issues of our time, the modernization of industrial heating systems becomes the center of attention for many academic researchers. One of the known methods to meet this progressive problem in industry is to modify the combustion system by using pure oxygen or oxygen-enriched air as the primary oxidizer. These methods, where the former is called oxy-fuel combustion, have been extensively investigated and also occasionally employed in industry [1].

The technology of oxy-fuel combustion, combined with flue gas recirculation, was introduced by Horn and Steinberg [2] and Abraham et al. [3], in the early eighties. Specifically, Abraham et al. mainly focused on oxy-fuel combustion for improving the Enhanced Oil Recovery (EOR), and Horn and Steinberg addressed the environmental impacts in energy generation systems. Afterwards, this technology received even more attention in research due to the increased incentives to decrease the $\mathrm{CO}_{2}$ levels in industrial applications [4].

In 2006, Golchert et al. [5] performed a numerical CFD simulation on an aluminium melting furnace with varying concentrations of oxidants. They concluded that $\mathrm{NO}_{x}$ emissions increase with an increased temperature and/or nitrogen concentrations in the oxidizer. Later, Kim et al. [6] conducted an experimental investigation on $\mathrm{NO}_{x}$ emissions from oxyfuel combustion equipped with a flue gas recirculation (FGR) system, with $0.03 \mathrm{MW}$ and $0.2 \mathrm{MW}$ burner capacities. Their research indicates the effectiveness of the FGR technology to reduce the $\mathrm{NO}_{x}$ emissions during oxy-fuel combustion. In 
2008, Andersson et al. [7] experimentally studied the combustion chemistry in different combustion processes with respect to the $\mathrm{NO}_{x}$ formation in an oxy-fuel and oxy-air combustion. They showed that the $\mathrm{NO}_{x}$ emission is considerably reduced (up to $30 \%$ ) in oxy-fuel combustion compared to its identical air-firing system. A year later in 2009, Normann et al. [8] made another study on the available techniques for $\mathrm{NO}_{x}$ emission control in oxy-fuel processes. Their study indicated that even an implementation of the conventional $\mathrm{NO}_{x}$ control system in a first generation of oxy-fuel power plants is adequate to meet the emission regulation at the time. Later in 2010, Toftegaarda et al. [9] made an extensive literature study on oxy-fuel combustion with a special focus to investigate the combustion fundamentals such as flame temperature and emissions. They highlighted the deficiency of research in many areas related to oxy-fuel, with both pilot and plant testing, such as investigating the heat transfer profiles, emission levels, and optimal oxygen excess levels at the inlet and validating models to predict $\mathrm{NO}_{x}$ and the formation of $\mathrm{SO}_{3}$.

In the recent years, improvements in CFD modeling and the increasing usage of super computers made the CFD technique more accessible. These studies are mainly for investigating the possible design or optimizing methods for burners and furnaces. As a result, many researchers [1012] started to validate the CFD models for modeling the complicated case of oxy-fuel combustion.

In 2010, Johansson et al. [10] investigated the influence of different radiation models to simulate gas radiation in oxyfired boilers. Specifically, the following radiation models were tested: the weighted-sum-of-gray-gases model (WSGGM), the spectral line-based WSGGM, the two gray-gas approximations, and the Statistical Narrow Band (SNB) models. The comparisons between all the CFD results and experimental data show that the WSGGM is the most suitable choice of all models. This shows that this can be used with a low computational cost. The authors also discussed that this is even more important in complicated cases where both wall radiative fluxes and radiative source term are computed. Later in 2010, Yin et al. [13] derived a modified WSGGM which is suitable to use for both oxy-fuel and air-fuel CFD simulations. They compared their results with the widely used model predictions in the literature and derived a set of useful guidelines for how to model oxy-fuel combustion.

As a complement to the former works, Hjärtstam et al. [12] examined the gray and nongray CFD models for gas radiation. This was done for both oxy-propane and air-propane combustion systems. By comparing the predictions to the experimental data, it was shown that the nongray approach gives an accurate prediction of the source term in both combustion systems. Furthermore, it was found that the simplified gray model fails to predict the source term accurately. In 2014, Wang et al. [14] presented research results with a similar focus. Specifically, they ran several CFD cases to predict the gas heat transfer by using the gray gas model while they configured the accuracy by using the SNB model. They showed that the gray gas model can accurately predict the peak heat transfer flux location but that it overpredicts the heat flux and heat transfer rate by almost $23 \%$ for the examined cases.
Porter et al. [15] also investigated the radiative properties of the combustion gases using the P1 model and the Discrete Ordinate Model (DOM), where both models used a nongray and a gray method. They also concluded that the use of the gray gas model to simulate oxy-fuel combustion might cause large errors. Later, Wang et al. [16] used many results of the literature at the time and ran a parametric numerical study on a propane furnace. Specifically, they used the $k-\varepsilon$ model including a wall function to simulate turbulence, DOM to simulate radiation, and the Probability Density Function (PDF) model to calculate the combustion. Similarly, Yin et al. [13] made a parametric study on the use of WSGGM to fit the parameters for both the air and oxy-fuel combustion systems.

By summing up the results from all the former numerical investigations and many experimental studies, the following aspects have been found to characterize the oxy-fuel combustion:

(1) A drastic decrease in the flue gas volume and therefore an increase in the furnace efficiency and a reduction of the fuel consumption.

(2) A reduction of the $\mathrm{CO}_{2}$ emission.

(3) A higher flame temperature compared to conventional combustion systems.

(4) An increment in heat transfer, due to better radiative properties of the final products (this will result in increased productivity).

(5) Improved flame properties, with respect to flame stability, and ignition characteristics [17].

Parallel to all the proven advantages of this technology, many challenges were also observed. This was specifically reported in the experimental investigations and the industrial implementations of this technology in existing combustion systems. One of the biggest challenges was seen to be an undesirable increment in the formation of thermal $\mathrm{NO}_{x}$, in case of air infiltration. This is partly due to a very high local temperature (up to $2000^{\circ} \mathrm{C}$ ) in the flame region. Moreover, an undesirable temperature distribution and a nonuniform heat transfer ratio were also observed in many studies that employed this technology [18]. Overall, extensive efforts and research were carried out to find a suitable modification for oxy-fuel combustion, in order to get the advantages but avoid the undesirable effects. In this regard, the "flameless oxyfuel" technology was introduced in 1980, as one of the most promising solutions to decrease the environmental impact from combustion systems.

The special burner design in flameless oxy-fuel combustion systems surcharges a high internal flue gas recirculation (IFGR) in combination with the other characteristics of oxy-fuel burners. The enhancement of the mixing degree in this mode of the burner is achieved by obtaining an asymmetric oxygen injection with a high (near supersonic) velocity. In this configuration, the combustion is utilizing the advantage of a lower exhaust gas volume by using pure oxygen as the oxidant. Therefore, these types of flames are almost invisible and they are volumetrically spread alongside the chamber. The combination of these aspects promises 
TABLE 1: The detail of the three developed CFD models.

\begin{tabular}{|c|c|c|c|}
\hline & Turbulent model & Combustion model & $\begin{array}{c}\text { Radiation } \\
\text { model }\end{array}$ \\
\hline Model 1 & Standard $k-\varepsilon$ & $\begin{array}{l}\text { PDF in chemical } \\
\text { equilibrium }\end{array}$ & $\begin{array}{l}\text { DOM with } \\
\text { WSGGM }\end{array}$ \\
\hline Model 2 & Realizable $k-\varepsilon$ & $\begin{array}{c}\text { PDF in chemical } \\
\text { equilibrium }\end{array}$ & $\begin{array}{l}\text { DOM with } \\
\text { WSGGM }\end{array}$ \\
\hline Model 3 & Realizable $k-\varepsilon$ & PDF with SLFM & $\begin{array}{l}\text { DOM with } \\
\text { WSGGM }\end{array}$ \\
\hline
\end{tabular}

a higher efficiency, a much lower $\mathrm{NO}_{x}$ production, and a more uniform temperature profile along the heating zone compared to standard combustion systems $[1,19]$.

In 2006, Narayanan et al. [19] carried out experimental trials using a pilot furnace with different burner configurations, including the flameless oxy-propane. Some of the results from this trial, which were done at Linde AGA in Stockholm, are used in the study. Specifically, they measured the local temperature and gaseous species for different burner types, including a flameless oxy-propane, with the focus on characterizing and comparing the $\mathrm{NO}_{x}$ formation. They pointed out several advantages of flameless oxy-flame burners in comparison to 4 other types of burner, such as a lower $\mathrm{NO}_{x}$ formation ratio and a better temperature uniformity $[19,20]$.

Even though using a flameless oxy-fuel combustion system has been proven to be a good solution to many industrial applications, there is a big scarcity of studies in this area. In particular, a combination of numerical and experimental studies is rare. Thus, this study will target this gap by providing predicted numerical as well as experimental results. Initially, a basic CFD model is developed evaluating the choice of turbulence model and successively investigating the implications of considering a combustion model at either infinite rate or the more computationally expensive steady laminar flamelet model (SLFM). These combinations of submodels are summarized in Table 1. Thereafter, the results are compared with experimental data taken from the experiment trial by Linde AGA in 2005. The authors believe the current results will highlight the applicability of adjusting and employing this new combustion technology in industrial applications, for the benefit of the environment.

\section{Material and Methods}

2.1. Experimental Procedure and Furnace Configuration. The experimental trial was done by Linde AGA in 2005, using a $200 \mathrm{~kW}$ pilot cylindrical furnace. The experiment at the time was done as a comparative study on different types of burners and their operational conditions [20]. However, in this study, the data from flameless oxy-fuel burner is solely used. During the initial stage when the furnace atmosphere was at the room temperature, the burner started the heating process with a conventional combustion. After reaching the limit of the self-ignition temperature in the furnace $\left(727^{\circ} \mathrm{C}\right)$, the burner started the combustion in the flameless oxy-fuel mode. Propane was used as fuel in this study, as it is a very desirable

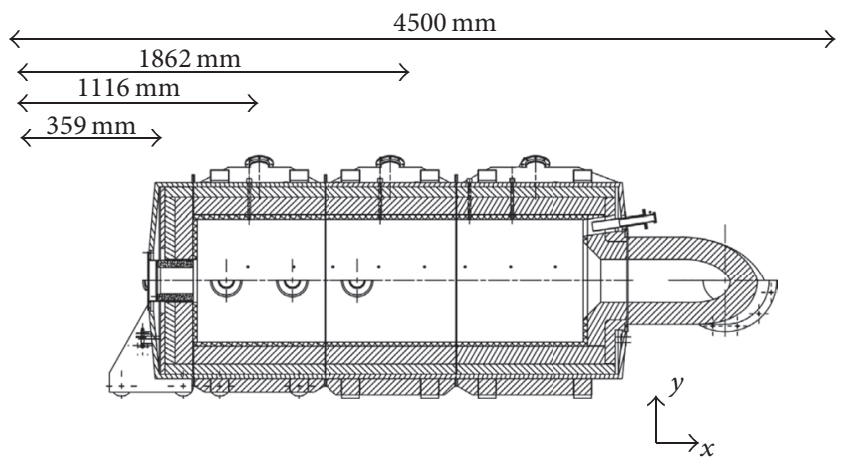

FIGURE 1: Furnace configuration.

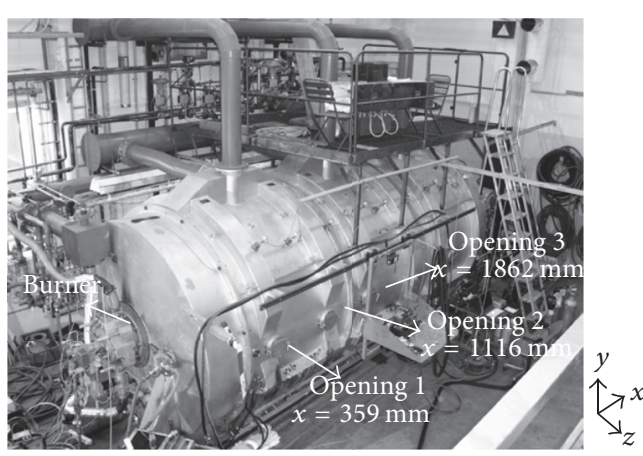

FIgUre 2: A photo of the furnace including the three openings.

fuel to employ in industrial applications and the oxidizer was pure oxygen.

The cylindrical semi-lab scale furnace had a $1.5 \mathrm{~m}$ diameter and $4 \mathrm{~m}$ length. The burner is installed in the front wall, in a coaxial direction with the length of the furnace. Also, the furnace was isolated with three layers consisting of $50 \mathrm{~mm}$ Saffil fibre modules, a $200 \mathrm{~mm}$ SuperG ramming mix, and a 115 mm G-23 insulating brick [19]. Also 16 S-type thermocouples were installed on the furnace wall at positions of $20 \mathrm{~mm}$ under the insulation layer. These thermocouples were used for constant monitoring of the "furnace wall temperature." This configuration is illustrated in Figure 1. The conical openings, where the probe is horizontally moved across the $x$-axis, are located at the following three levels of $x=359 \mathrm{~mm}$, $x=1116 \mathrm{~mm}$, and $x=1862 \mathrm{~mm}$ (Figures 2 and 3) [19].

The measurements were done by employing suction pyrometers to measure the temperature, radiation, heat flux, and total surface heat transfer with minimized radiation errors [20, 21]. The gas composition was measured, using a water-cooled gas-sampling probe to extract the gas from the desired measurements points. Furthermore, gas chromatography was used to analyze the dry-based compositions [19].

2.2. Burner. A REBOX ${ }^{\circledR}$ oxy-fuel flameless burner, which is developed and commercialized by Linde AGA in Sweden, was used in this study. The burner, which is shown in Figure 4, has two injecting nozzles for oxygen and one for fuel. One essential aspect of these burner types is the injection velocity which directly affects the characterization of the combustion. 


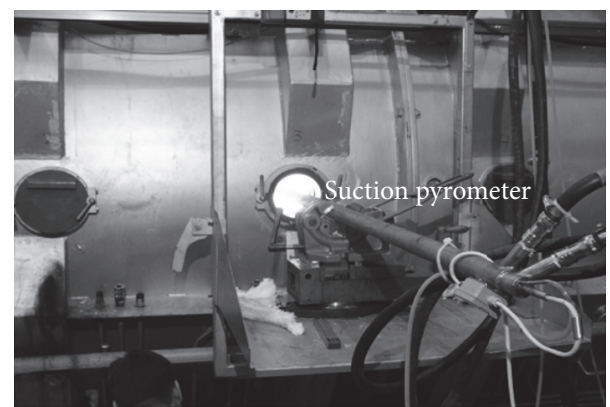

FIGURE 3: A photo of the positioning of the suction pyrometer.

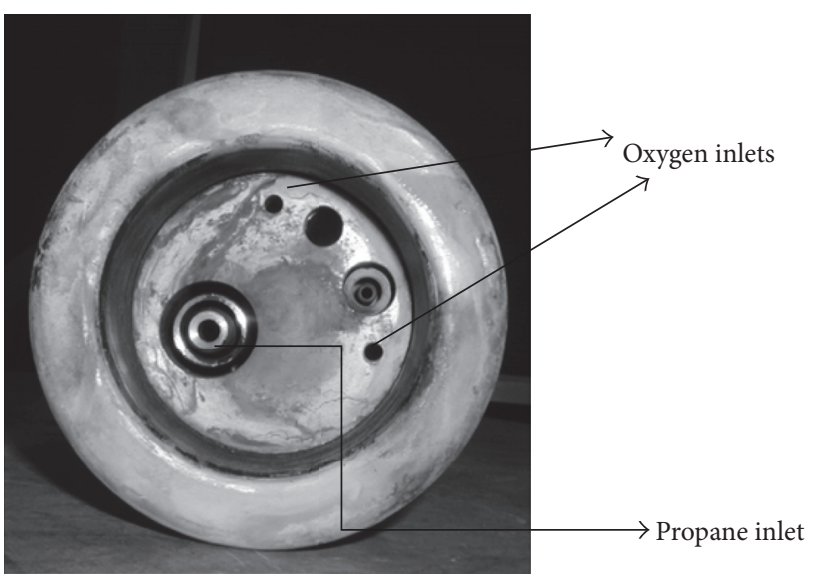

FIGURE 4: A photo of the burner configuration including the oxygen and propane inlets.

This near sonic injection velocity eventuates an excellent mixing ratio for the oxidant and fuel, which forms large eddies due to a strong turbulence. This, in turn, causes an internal mixing of flues gases, oxygen, and fuel in the flame region. The form of the flame in this type of combustion system is very spread, which is also a reason why it is called a volumetric combustion [22]. The special design of the flameless oxy-fuel combustion requires high speed (near sonic) injection velocities for both oxygen and propane. Additionally, the asymmetric positioning of feeding nozzles for inlets will cause a turbulent flow with internal flue gas recirculation effects and eddy formations.

2.3. Suction Pyrometers. A lot of studies have been done to validate temperature measurements inside the furnaces (high temperature environments), partly due to the errors that radiation causes. Specifically, Blevins and Pitts [23] have reported that, in high temperature conditions, corresponding temperatures above $727^{\circ} \mathrm{C}$, radiation errors can be several hundred degrees. In order to measure the gas temperature in a radiative condition, IFRF developed and introduced "suction pyrometers" (Figure 5) in 1998. These devices eliminate the errors due to radiation to a very big extent. The details of the uncertainty limits for each measured parameter at $1300^{\circ} \mathrm{C}$ are shown in Table 2, while the accuracy of the thermocouple was measured to be $\pm 8^{\circ} \mathrm{C}$ at $1300^{\circ} \mathrm{C}[20]$.

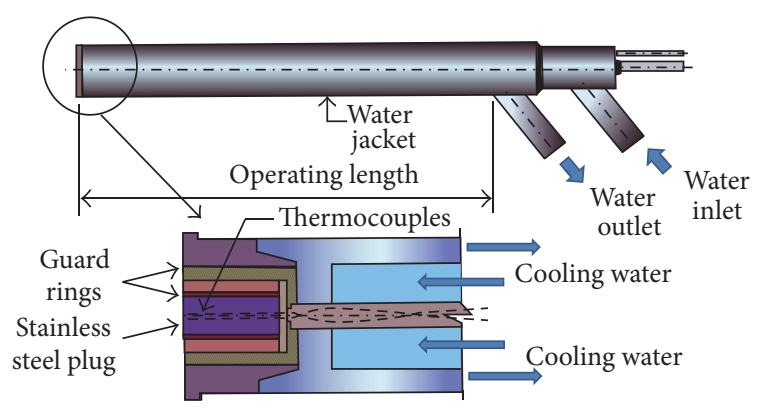

FIGURE 5: A sketch of the structure of the suction pyrometer including essential parts.

TABLE 2: Uncertainty limits for each measured parameter at $1300^{\circ} \mathrm{C}$.

\begin{tabular}{lc}
\hline Measurement & $\begin{array}{c}\text { The minimum and } \\
\text { maximum uncertainties }\end{array}$ \\
\hline Flue gas temperature & $2.2 \%-5.7 \%$ \\
Heat fluxes & $2 \%-6 \%$ \\
Flue gas composition & $1 \%-8 \%$
\end{tabular}

The repeatability of the test was also investigated. Specifically, the measurements were repeated three times by using identical experimental conditions. The standard deviation for the flame temperature, total heat flux, and radiative heat flux were $4 \%, 6.5 \%$, and $2 \%$, respectively. The repeatability trial to study the flue gas composition showed a maximum and minimum standard deviation of $8 \%$ and $4 \%$, respectively [20].

\section{Mathematical Model}

3.1. Model Assumptions. The 3-dimensional mathematical model is based on the following assumptions:

(1) The model is a pilot-scale furnace based on the geometry shown in Figure 1.

(2) The standard equations for continuity and momentum in Fluent are used [24].

(3) Turbulence is described using either the standard $k-\varepsilon$ turbulence model [25] or the realizable $k-\varepsilon$ turbulence model [26].

(4) The walls are treated with the standard wall function recommended by Launder and Spalding [25].

(5) Chemical reactions are considered using either equilibrium or the steady laminar flamelet model. Local variations in turbulent mixing of the species are considered using a Probability Density Function.

(6) Radiation is described using discrete ordinate method with the weighted-sum-of-gray-gases model.

(7) Leakage of air is neglected, so all $\mathrm{NO}_{x}$ products are eliminated.

3.2. Turbulence. The standard $k-\varepsilon$ model has been validated for similar problems by previous authors [16]. However, it is known for being overly diffusive and lacking accuracy in 
cases with rotating flows and prediction of spreading rate of round jet flows [27], whereas the realizable $k-\varepsilon$ model has been shown to outperform the standard $k-\varepsilon$ model on these points [28]. Therefore, in order to investigate which turbulence model is better suited in this case, a comparison of the standard $k-\varepsilon$ model [25] and the realizable $k-\varepsilon$ model [26] is made.

\subsubsection{Standard $k-\varepsilon$}

$$
\begin{aligned}
\frac{\partial(\rho k)}{\partial t}+\frac{\partial\left(\rho k u_{i}\right)}{\partial x_{i}}= & \frac{\partial}{\partial x_{j}}\left[\left(\mu+\frac{\mu_{t}}{\sigma_{k}}\right) \frac{\partial k}{\partial x_{j}}\right]+G_{k}+G_{b} \\
& -\rho \varepsilon \\
\frac{\partial(\rho \varepsilon)}{\partial t}+\frac{\partial\left(\rho \varepsilon u_{i}\right)}{\partial x_{i}}= & \frac{\partial}{\partial x_{j}}\left[\left(\mu+\frac{\mu_{t}}{\sigma_{\varepsilon}}\right) \frac{\partial \varepsilon}{\partial x_{j}}\right] \\
& +C_{1 \varepsilon} \frac{\varepsilon}{k}\left(G_{k}+C_{3 \varepsilon} G_{b}\right) \\
& -C_{2 \varepsilon} \rho \frac{\varepsilon^{2}}{k}+S_{\varepsilon} \\
C_{3 \varepsilon}= & \tanh \left|\frac{v_{\|}}{u_{\perp}}\right|
\end{aligned}
$$

where $\sigma_{k}=1.0, \sigma_{\varepsilon}=1.3, C_{2 \varepsilon}=1.92, C_{1 \varepsilon}=1.44, G_{k}$ represents the generation of turbulence kinetic energy due to the mean velocity gradients, and $G_{b}$ is the generation of turbulent kinetic energy due to the buoyancy. $v_{\|}$and $u_{\perp}$ are the velocity components parallel and perpendicular to the gravity vector, respectively.

The turbulent viscosity is given as follows:

$$
\mu_{t}=\rho C_{\mu} \frac{k^{2}}{\varepsilon}
$$

where $C_{\mu}=0.09$.

3.2.2. Realizable $k$ - $\varepsilon$. The transport equation for turbulent kinetic energy, $k$, is the same as (1) with different constants, while turbulent dissipation, $\varepsilon$, is as follows:

$$
\begin{aligned}
\frac{\partial(\rho \varepsilon)}{\partial t}+\frac{\partial\left(\rho \varepsilon u_{j}\right)}{\partial x_{j}} & =\frac{\partial}{\partial x_{j}}\left[\left(\mu+\frac{\mu_{t}}{\sigma_{\varepsilon}}\right) \frac{\partial \varepsilon}{\partial x_{j}}\right]+\rho C_{1} S_{\varepsilon} \\
& -\rho C_{2} \frac{\varepsilon^{2}}{k+\sqrt{\nu \varepsilon}}+C_{1 \varepsilon} \frac{\varepsilon}{k} C_{3 \varepsilon} G_{b} \\
C_{1} & =\max \left[0.43, \frac{\eta}{\eta+5}\right], \\
\eta & =S \frac{k}{\varepsilon} \\
S & =\sqrt{2 S_{i j} S_{i j}},
\end{aligned}
$$

where $\sigma_{k}=1.0, \sigma_{\varepsilon}=1.2, C_{2}=1.9, C_{1 \varepsilon}=1.44$, and $C_{3 \varepsilon}$ is described by (3).
The turbulent viscosity is also described by (4), with the difference that $C_{\mu}$ is a function in the realizable $k-\varepsilon$ model.

3.3. Combustion. For nonpremixed combustion, the thermochemistry can thus be reduced to a conserved scalar quantity called the mixture fraction $(f)$ :

$$
f=\frac{Z_{i}-Z_{i, \mathrm{ox}}}{Z_{i, \text { fuel }}-Z_{i, \mathrm{ox}}},
$$

where $Z_{i}$ stands for the $i$ th species mass fraction and the subscripts ox and fuel stand for the oxidizer stream and fuel stream, respectively. For a nonadiabatic system such as the present model, the instantaneous species mass fraction, density, or temperature is a function of both mixture fraction and enthalpy.

A PDF is used to consider subgrid local fluctuations between the species. Furthermore, the burner causes a rapid chemical reaction with a highly strained flame shape, which leads to forming conspicuous amounts of nonequilibrium species. Thus, to investigate if the infinite rate (local equilibrium) is good enough to describe this system, a comparison is made between the infinite rate and the SLFM. The latter model predicts the chemical nonequilibrium flame straining, caused by turbulence.

In SLFM thermochemistry parameters are a function of mixture fraction and the strain rate or, equivalently, dissipation rate $(\chi)$ :

$$
\chi=2 D|\nabla f|^{2},
$$

where $D$ is the diffusion coefficient.

Consequently, in this method, the thermochemistry parameters are fully parameterized by mixture fraction $(f)$, dissipation rate $(\chi)$, and enthalpy $(H)$. However, in order to moderate the costs of calculation in SLFM, the effect of heat loss/gain $(H)$ is neglected. Therefore, the following formulation will be used to calculate the thermochemical parameters:

$$
\bar{\Phi}=\iint \Phi\left(f, \chi_{\mathrm{st}}\right) p\left(f, \chi_{\mathrm{st}}\right) d f d \chi_{\mathrm{st}}
$$

where $\Phi$ represents species mass fractions and temperature and $\chi_{\text {st }}$ represents the stoichiometric dissipation rate.

3.4. Radiation. Oxy-fuel combustion strongly promotes the radiative heat transfer, since a higher volume fraction of $\mathrm{CO}_{2}$ and $\mathrm{H}_{2} \mathrm{O}$ exists in the flue gas composition, in comparison with air combustion [11]. Thus, a careful consideration of radiation model is needed.

In this problem, there are no participating media in the radiative space, so the effect of scattering will be cancelled. This will transform the general radiative transfer equation (RTE) into the following relationship:

$$
\frac{d I_{v}}{d_{s}}=k_{v} I_{b v}-k_{v} I_{\nu},
$$

where $I_{v}$ stands for the intensity in the wavelength, $k_{v}$ is the absorption coefficient, and $I_{b v}$ is the black body radiative 


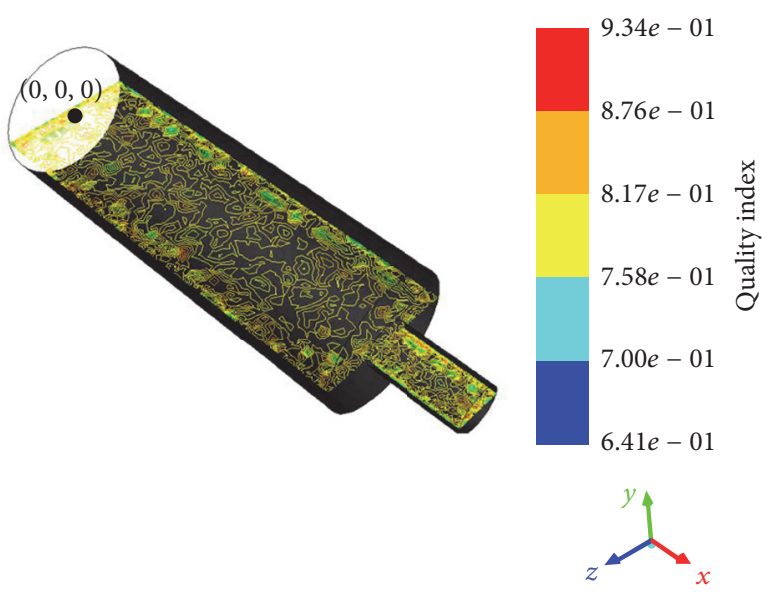

Figure 6: Contours of orthogonal quality.

intensity [10]. By integrating this equation over the radiative path of $S$ and after performing a spectral averaging over a band $k$, the following equation will be obtained for each cell [10]:

$$
\bar{I}_{v_{k, n}}=\bar{I}_{v_{k, 0}} \bar{\tau}_{v_{k, 0 \rightarrow n}}+\sum_{i=0}^{n-1}\left(\bar{\tau}_{v_{k, i+1 \rightarrow n}}-\bar{\tau}_{v_{k, i \rightarrow n}}\right) \bar{I}_{b v_{k, i+1 / 2}},
$$

where overbar stands for a spectral average over a band $k$, index $i$ refers to spatial discretization, and $\bar{\tau}_{\gamma k}$ can be expressed as

$$
\bar{\tau}_{v k}=1-\bar{a}_{v k}
$$

where $a$ is the absorption coefficient.

In the nongray model, this equation will be solved once for a single band range, by using a constant absorption coefficient. However, in oxy-fuel combustion, the assumption of a constant absorption coefficient reduces the accuracy [29-32].

The DOM was used to solve the RTE for a number of discrete solid angles. By incorporating the domain based standard WSGGM, reasonable predictions of wall heat fluxes and radiative source terms can be expected [10]. The trick in WSGGM is that the total emissivity over the distance $\vec{s}$ can be presented as follows [33]:

$$
\mathcal{\varepsilon}=\sum_{i=0}^{I} a_{\varepsilon, i}(T)\left(1-e^{-k_{i} p \vec{s}}\right)
$$

where $a_{\varepsilon, i}$ stands for the emissivity weighting factor for the $i$ th fictitious gray gas and the quantity in the bracket stands for the $i$ th fictitious gray gas emissivity. Furthermore, $k_{i}$ is the absorption coefficient of the $i$ th gray gas, $p$ is the summation of the partial pressure of all absorbing gases, and $\vec{s}$ is the path length.

3.5. Domain. The domain of the furnace is illustrated in Figure 6. The mesh was selected to be unstructured with a total node number of 1300000 on the total domain. The mesh structure is finer on the edges close to the wall boundaries and in the area of flame formation. The minimum orthogonal
TABLE 3: Boundary condition of the inlet flows.

\begin{tabular}{lcc}
\hline & Fuel & Oxygen \\
\hline Flow rates, $\mathrm{Nm}^{3} / \mathrm{h}$ & 7.7 & 40.4 \\
Low heat value, $\mathrm{MJ} / \mathrm{m}^{3}$ & 46.3 & \\
Composition, $\%$ & $\mathrm{C}_{3} \mathrm{H}_{8}=100 \%$ & $\mathrm{O}_{2}=100 \%$ \\
Temperature, ${ }^{\circ} \mathrm{C}$ & 25 & 20 \\
Density, $\mathrm{kg} / \mathrm{Nm}^{3}$ & 2.02 & 1.411 \\
Density, $\mathrm{kg} / \mathrm{m}^{3}$ & 2.016 & 3.3 \\
Velocity, $\mathrm{m} / \mathrm{s}$ & 94 & 351.7 \\
Diameter of nozzle, $\mathrm{mm}$ & 6 & $4 \times 2$ \\
\hline
\end{tabular}

quality is 0.641 which is adequate regarding general limitations. Figure 6 shows the contours of orthogonal quality alongside a horizontal plane in the middle of the simulated furnace.

\section{Boundary Conditions}

The capacity of the experimental furnace is $200 \mathrm{~kW}$. Details of the inlet combustion boundary condition are shown in Table 3. The turbulent intensity and hydraulic diameter for the propane nozzle were calculated to be $6 \%$ and $6 \mathrm{~mm}$, respectively. Furthermore, for the oxygen nozzles the corresponding values are $5 \%$ and $4 \mathrm{~mm}$, respectively.

Specific heat and thermal conductivity for the interior walls are set to $2650 \mathrm{~kg} / \mathrm{m}^{3}, 880 \mathrm{~J} / \mathrm{kg}-\mathrm{K}$, and $180 \mathrm{~W} / \mathrm{m}-\mathrm{K}$, respectively. These are calculated regarding the special case of isolations on refractory walls in this study.

The standard wall function was used to bridge near wall layer with the mean flow in (1) and (2), where $Y^{+}$was calculated to be between 60 and 200 .

The density and specific heat of the mixture are calculated locally according to the PDF table. Also, the absorption coefficient of the mixture is calculated by using WSGGM. The boundary condition on the walls of the furnace was considered as a fixed temperature of $1200^{\circ} \mathrm{C}$. The outlet is selected as a pressure type with no gauge pressure. Also the turbulent intensity and hydraulic diameter of the outlet were calculated to have the values of $5 \%$ and $500 \mathrm{~mm}$, respectively.

\section{Results and Discussions}

In this section, predicted CFD results for different parameters, namely, temperature and gaseous species $\left(\mathrm{CO}, \mathrm{CO}_{2}\right.$, and $\mathrm{O}_{2}$ ), are compared with experimental results. These predicted results are taken from three different CFD models, namely, models 1, 2, and 3. For turbulence, model 1 uses the standard $k-\varepsilon$ model, whereas models 2 and 3 use the realizable $k-\varepsilon$ model. For combustion, a PDF is used in combination with the chemical reactions assumed at infinite rate (equilibrium) in models 1 and 2, whereas for model 3 the PDF is combined with reactions at finite rates (nonequilibrium) with the SLFM.

The accuracy of locating the probe for taking the experimental data is within $\pm 10 \mathrm{~mm}$. The suction pyrometer has an insertion diameter of $10 \mathrm{~mm}$, which sucks the regional flue gas with a high velocity. Therefore, the experimental data 


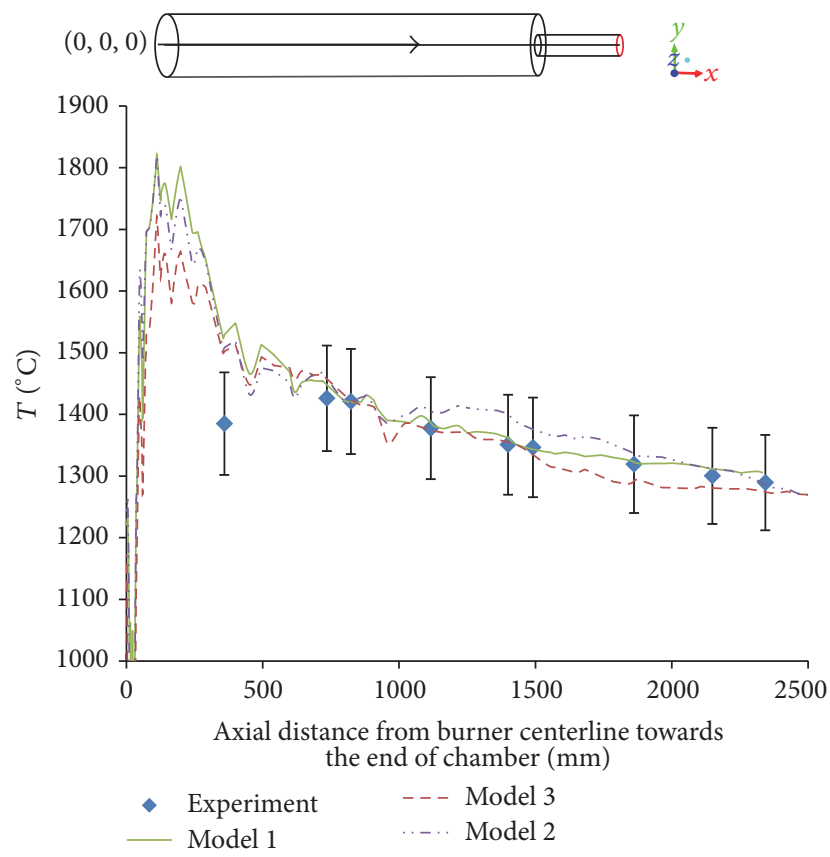

FIGURE 7: Temperature magnitudes on the axial line of the chamber from burner centerline towards the end of the chamber.

represent an average volume of the flue gas composition in the area of the point of measurement. Also the experiments have been done 3 times for every point so a stable magnitude for each point has been determined. The scatter associated with the measured data is $6 \%$ [20].

5.1. Temperature. Figure 7 shows the temperature magnitudes on the axial line of the chamber on its length, for both experimental data and calculated data from three CFD models. This measurement is done on an axis starting from burner center and towards the end of the chamber.

Overall, in regions away from the burner, all of the CFD results are within the uncertainty of the experiments, as shown in Figure 7. The measurement point at $359 \mathrm{~mm}$ is suspected to have additional uncertainty than is shown by the error bars.

In addition to this temperature measurement, and in order to get a comprehensive picture of the temperature profile, measurements were carried out both in the flame region and in a region further away from the flame. In particular, the measurements have been done at three different distances away from the burner. These three lines are located at the distances $359 \mathrm{~mm}, 1116 \mathrm{~mm}$, and $1862 \mathrm{~mm}$ from the burner wall, with the origin $(z=0)$ at the axis of the center of the burner. This is clearly shown in Figure 2.

Figures 8(a), 8(b), and 8(c) show the temperature data measured at these points and the corresponding calculated data from the three different CFD models, at the locations $359 \mathrm{~mm}$ (a), $1116 \mathrm{~mm}$ (b), and $1862 \mathrm{~mm}$ (c) from the burner.

As shown in Figure 8(a), there is a major improvement in predicting the temperature in regions close to the reaction

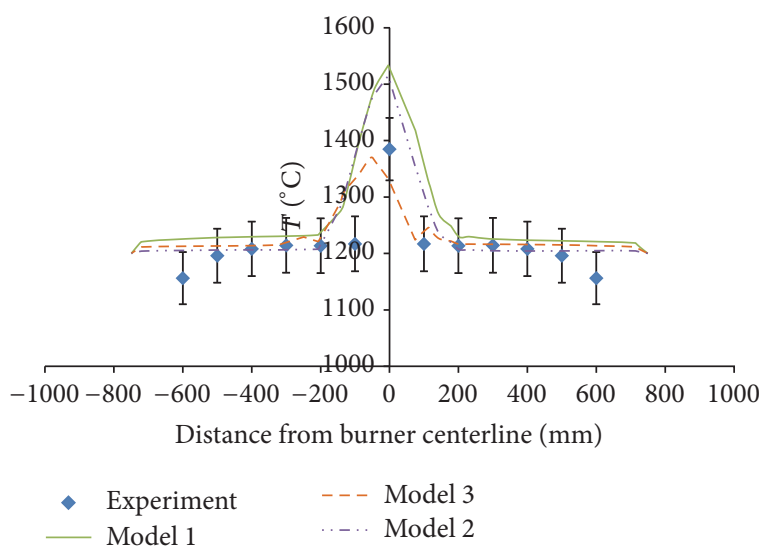

(a)

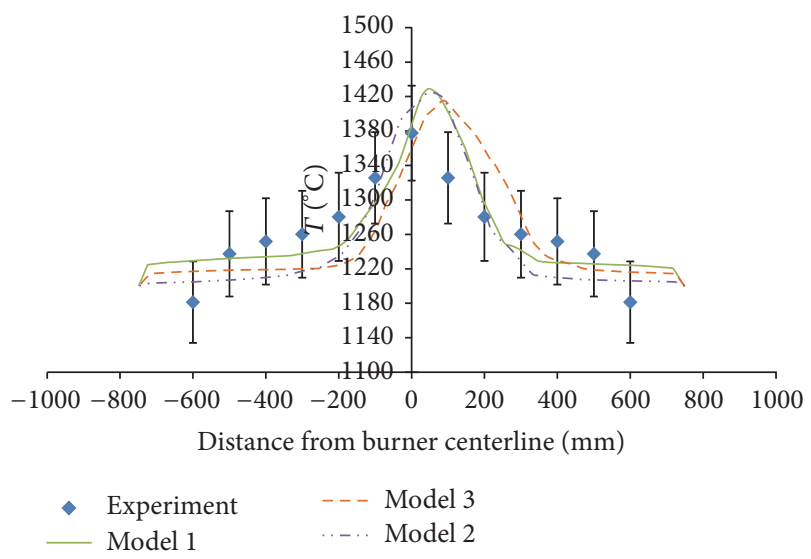

(b)

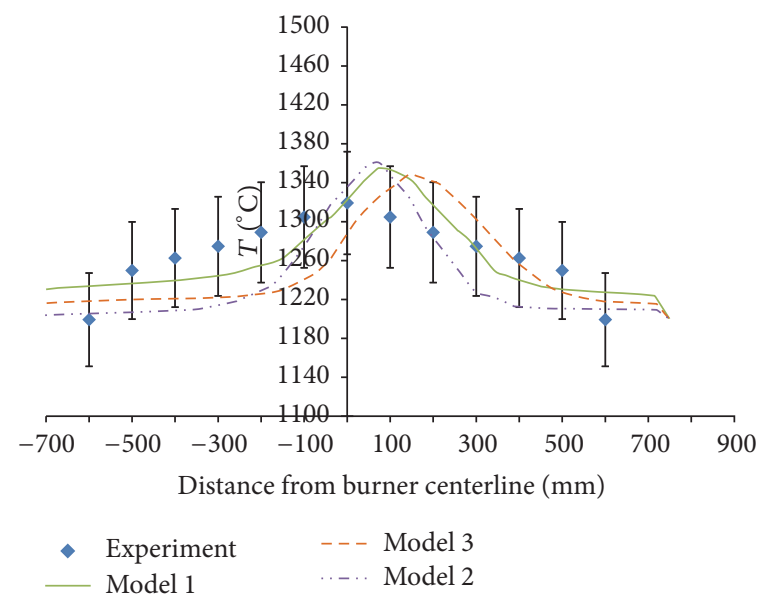

(c)

FIGURE 8: Temperature predictions and measurements of the radial axis at the positions (a) $x=359 \mathrm{~mm}$, (b) $x=1116 \mathrm{~mm}$, and (c) $x=1862 \mathrm{~mm}$.

zone in model 3 compared to models 1 and 2 . The corresponding deviation from experiments reduces from $7.6 \%$ to $1.2 \%$ from model 1 to model 3 , respectively. These results accentuate the difference of considering infinite rate reactions compared to finite rate reactions, in reaction regions where stretch effects are not negligible. A better realization about 


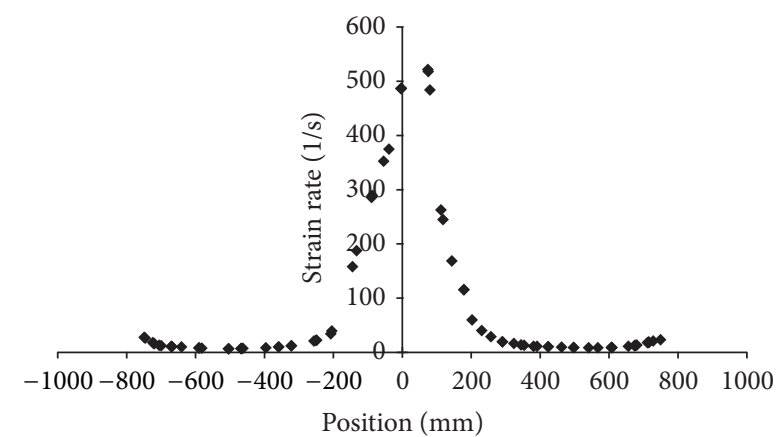

FIGURE 9: Strain rate along the radial line of $x=359 \mathrm{~mm}$, close to the flame region.

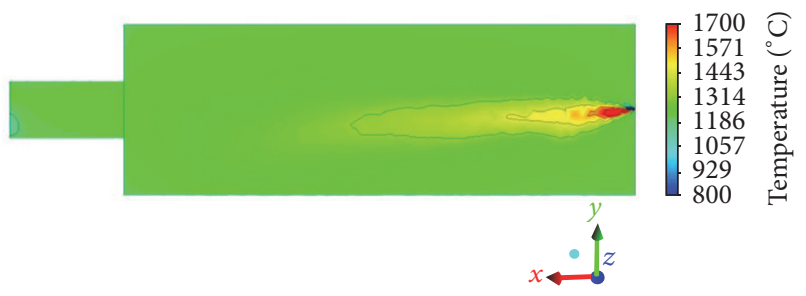

FIGURE 10: Temperature distribution profile on the $x-y$ plane in the middle of the chamber, model 1.

this might be achieved if one looked at the strain rate in this region, which is shown in Figure 9. The high strain rate close to the reaction zone explicitly illustrates the departure from chemical equilibrium in this region.

The improvements from model 1 to model 2 on the other hand are not significant, though the predicted temperature is generally lower in model 2 . This is due to the tendency of the standard $k-\varepsilon$ turbulence model to overpredict the turbulence of the flow, which leads to a higher mixing rate and consequently a higher temperature level.

In Figures 8(b) and 8(c), an asymmetric temperature distribution is obvious, which resembles the nature of flameless oxy-fuel burners. The discrepancy between the injection velocities for the fuel and oxygen and the asymmetric burner design, while increasing the mixing ratio, will also lead to a deviated flow path inside the chamber. Figure 10 illustrates this in a more coherent way.

\subsection{Gas Composition}

5.2.1. Flame Region. Figures 11(a), 11(b), and 11(c) show the predicted concentrations by the CFD models and the measured corresponding values of volume percentages of $\mathrm{O}_{2}, \mathrm{CO}_{2}$, and $\mathrm{CO}$ on the dry basis. These data are from the flame region ( $359 \mathrm{~mm}$ from the burner side) on a half radial axis, starting from $100 \mathrm{~mm}$ from centerline towards the chamber wall. Results extrapolated from the models are in correspondence with the sampling locations.

According to Figure 11(a), the assumption of infinite rate reactions eventuates a $9 \%$ deviation from experimental data (for model 1 and model 2). This assumption, which considers a nonequilibrium chemistry, results in the formation of

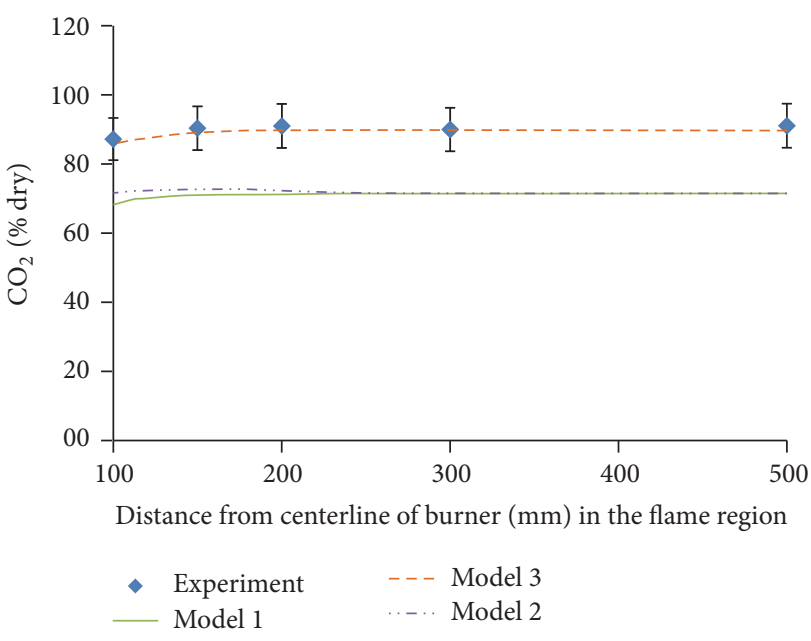

(a)

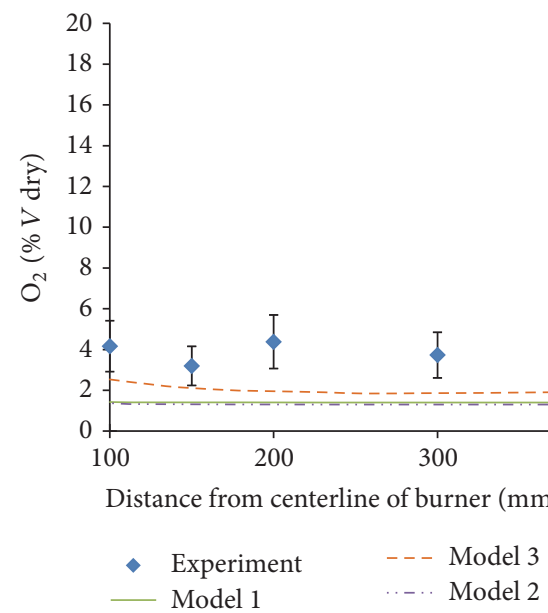

(b)

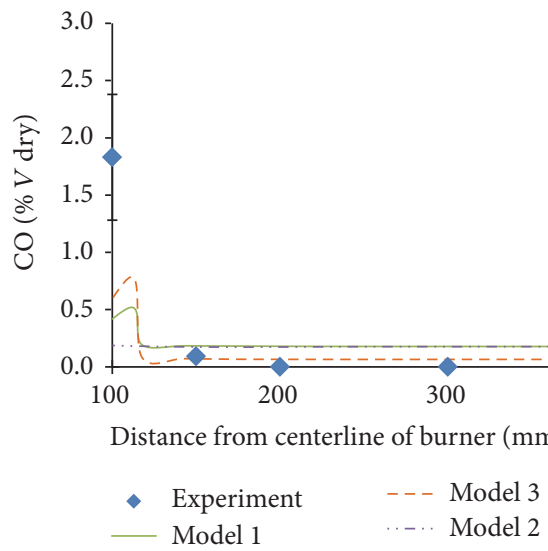

(c)

Figure 11: (a) Predicted and measured $\mathrm{CO}_{2}$ volume percentage (dry basis) on the half radial axis at $x=359$. (b) $\mathrm{O}_{2}$ volume percentage (dry basis) at the half radial axis at $x=359$. (c) CO volume percentage (dry basis) at the half radial axis at $x=359$.

a large amount of intermediate radicals in the reaction zone. On the contrary, modifying the turbulent model does not 


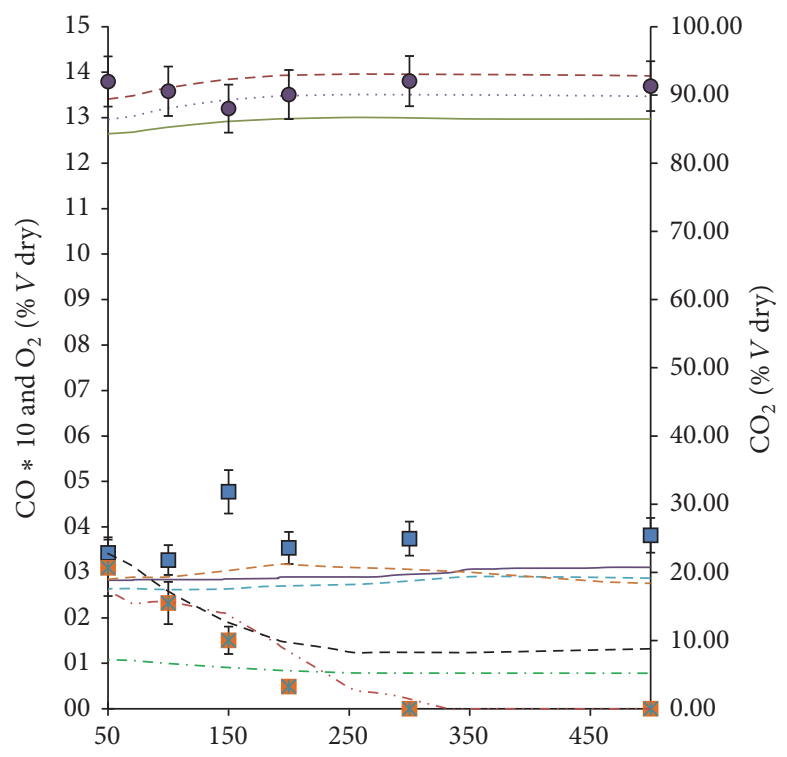

Radial distance from centerline of burner $(\mathrm{mm})$ at $x=1116$

$$
\begin{array}{ll}
\square \mathrm{O}_{2} \text { experiment } & \cdots-\cdot \mathrm{CO} * 10 \text { model } 3 \\
-\mathrm{CO} * 10 \text { experiment } & ---\mathrm{CO} * 10 \text { model } 2 \\
---\mathrm{O}_{2} \text { model } 2 & -\mathrm{CO}_{2} \text { model } 1 \\
--\cdot \mathrm{CO} * 10 \text { model } 1 & ---\mathrm{CO}_{2} \text { model } 3 \\
-\mathrm{O}_{2} \text { model 1 } & \cdots \cdots \mathrm{CO}_{2} \text { model } 2 \\
---\mathrm{O}_{2} \text { model 3 } & \circ \mathrm{CO}_{2} \text { experiment }
\end{array}
$$

(a)

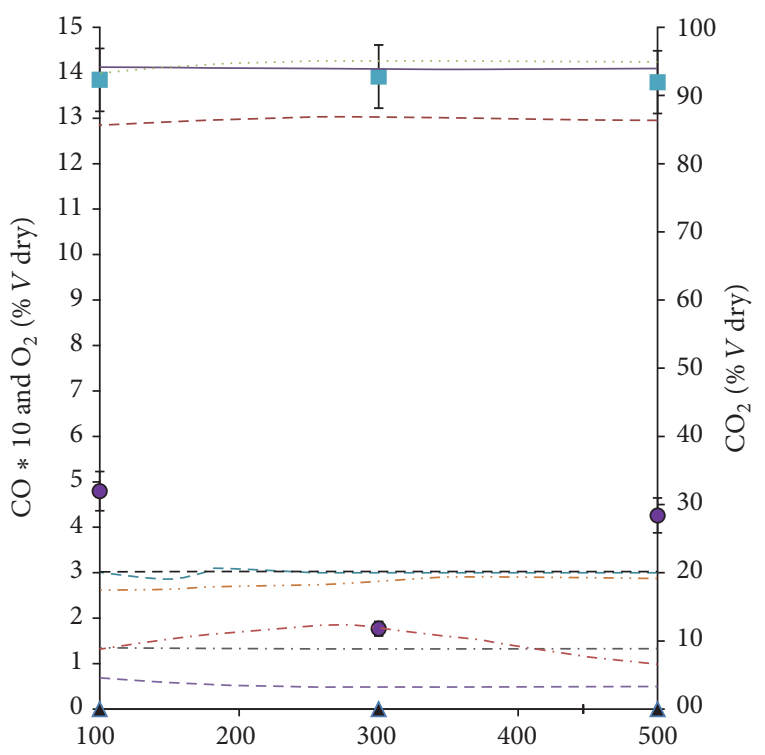

Radial distance from centerline of burner $(\mathrm{mm})$ at $x=1862$

$$
\begin{array}{ll}
\text { - } \mathrm{O}_{2} \text { experiment } \\
\text { ^ } \mathrm{CO} * 10 \text { experiment } \\
.-. & \mathrm{CO} * 10 \text { model } 1 \\
---\mathrm{O}_{2} \text { model } 1 \\
\cdots-\cdots \mathrm{O}_{2} \text { model } 3 \\
\text {-.- } \mathrm{CO} * 10 \text { model } 3
\end{array}
$$

- - $\mathrm{O}_{2}$ model 2

- $\mathrm{CO}_{2}$ experiment

$---\mathrm{CO}_{2}$ model 1

$-\mathrm{CO}_{2}$ model 3

$\mathrm{CO}_{2}$ model 2

- $\mathrm{CO} * 10$ model 2

(b)

FIGURE 12: Predicted and measured volume percentages of $\mathrm{CO} * 10, \mathrm{CO}_{2}$, and $\mathrm{O}_{2}$ (dry basis) at (a) $x=1116 \mathrm{~mm}$ and (b) $x=1862 \mathrm{~mm}$.

show considerable improvements in predicting the gaseous species in the flame region.

5.2.2. Chamber Region. Figures $12(\mathrm{a})$ and 12(b) show the predicted and measured values of the volume percentages of $\mathrm{O}_{2}, \mathrm{CO}_{2}$, and $\mathrm{CO} * 10$ on the dry basis. Results are taken from the radial axis located at $1116 \mathrm{~mm}$ and $1862 \mathrm{~mm}$ from the burner $(z=0, x=0)$, respectively. The axis reflecting the $\mathrm{CO}_{2}$ values is shown on the right-hand side of the figure, while the common axis for $\mathrm{CO} * 10$ and $\mathrm{O}_{2}$ dry volume percentages is shown on the left-hand side.

In the chamber region, which stands for the overall chamber volume, the predictions from all the 3 models are reasonably close to the experimental data. Specifically, the maximum deviation between the predicted and measured data, predicted by model 1 , is seen for $\mathrm{CO}$ at $1116 \mathrm{~mm}$ from the origin (11\%) and for $\mathrm{O}_{2}$ in $1862 \mathrm{~mm}$ from the origin (8\%). This deviation is decreased with the realizable $k$ - $\varepsilon$ model, while it is reduced to $7 \%$ for $\mathrm{CO}$ at $1116 \mathrm{~mm}$ from the origin. The predicted $\mathrm{CO}$ by model 3 and experimental data are following the same trend, which shows the strength of this model. One can also note that, at some occasions, a nonharmonized behavior is seen in the experimental data. This raises the suspicion of some imperfections in collecting these data, like for $\mathrm{CO}$ in $z=50 \mathrm{~mm}, \mathrm{O}_{2}$ in $z=300 \mathrm{~mm}$, and $\mathrm{CO}_{2}$ in $z=150 \mathrm{~mm}$. Regarding this, $\mathrm{O}_{2}$ is well predicted by model 3 and less fine by model 1 and model 2 . $\mathrm{CO}_{2}$ prediction follows the same progression as in the flame region; model 3 , with considering the

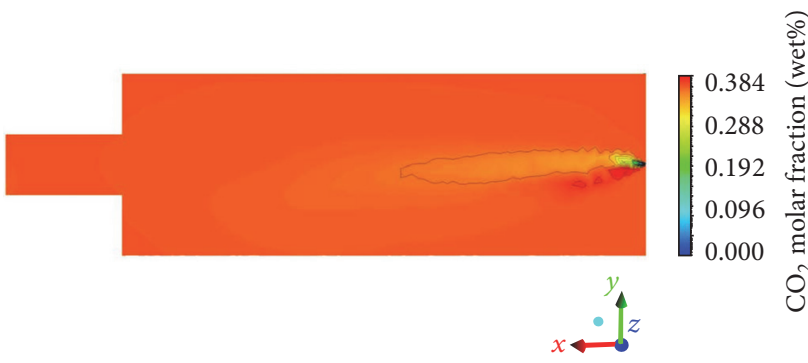

FIGURE 13: Distribution profile of volume percentage of $\mathrm{CO}_{2}$ (wet basis) on the $x-y$ plane in the middle of the chamber.

nonequilibrium effects, realizes the full formation of $\mathrm{CO}_{2}$ in contrast with the other two models. The improvement of $\mathrm{CO}_{2}$ predictions by model 2 compared to model 1 (by modifying turbulent model) is also noticeable, since both model 2 and model 3 are in very close agreement with experimental data in Figures 12(a) and 12(b). Model 3 and model 2 deviate 1.5\% and $2.2 \%$ from the experiments, respectively. In comparison, model 1 has a 6\% deviation $1862 \mathrm{~mm}$ away from the burner.

As it was observed and described for the temperature distribution profile, an asymmetric design of this type of burners forms a nonsymmetric distribution for the gaseous species as well as for the temperature. Figure 13, which shows the molar fraction of $\mathrm{CO}_{2}$, predicted by model 1 (given as the wet percentage), illustrates this in a more tangible way. 
TABLE 4: The measured and predicted amount of volume percentages (dry basis) of $\mathrm{O}_{2}, \mathrm{CO}_{2}$, and $\mathrm{CO}$ at the exhaust.

\begin{tabular}{lccc}
\hline & Predictions & $\begin{array}{c}\text { Experimental } \\
\text { results }\end{array}$ & $\begin{array}{c}\% \text { inconsistency } \\
\text { in total }\end{array}$ \\
\hline$(\% V$ dry $) \mathrm{O}_{2}$ & 2.1 & 2.8 & 13.32 \\
$(\% V$ dry $) \mathrm{CO}$ & 0 & 0 & 0 \\
$(\% V$ dry $) \mathrm{CO}_{2}$ & 91 & 93.5 & 2.63 \\
\hline
\end{tabular}

The measured and predicted amounts of the volume percentages (dry basis) of $\mathrm{O}_{2}, \mathrm{CO}_{2}$, and $\mathrm{CO}$ at the exhaust are shown in Table 4.

\section{Conclusions}

Three different sophisticated 3D CFD models have been developed and used to simulate a flameless oxy-fuel combustion and results were compared with experimental data from a pilot furnace. Model 2 and model 3 are the modified versions of model 1 with respect to turbulence and combustion models, respectively.

The following are the main findings in this study:

(i) Model 1 which was the least computationally intensive model used the standard $k-\varepsilon$ for turbulence and PDF with infinite rate reactions for combustion and had a good agreement in temperature between predicted and experimental data far away from the burner. Close to the burner, this model was inferior to the other models.

(ii) Model 2 showed clear improvements concerning gaseous species away from the burner radially. This is a direct cause of the realizable $k-\varepsilon$ model for turbulence. However, for temperature, large deviations still remain in the flame region.

(iii) Model 3 predicted both the temperature and the gaseous species well in all of the furnace by considering finite rate reactions as well as the realizable $k-\varepsilon$ model. The better prediction of temperature close to the burner was due to the consideration of finite reaction rate, which more accurately modeled the heat dissipation in the flame region. The improvement in prediction of gaseous species overall was due to the combination of the better combustion model description of the chemical reactions in the flame region and the more accurate turbulence description of the transport of combustion products.

This concludes that it is possible to accurately predict flameless oxy-fuel combustion, by using complex models, such as the realizable $k-\varepsilon$ model for turbulence and steady laminar flamelet model for combustion.

\section{Competing Interests}

The authors declare that they have no competing interests.

\section{Acknowledgments}

The experiment work has been done at Linde AGA, Sweden, which the authors gratefully acknowledge. Special thanks go to Ovako Sweden AB for financing the research. In addition, the authors are very thankful to Mohsen Saffari Pour at KTH for assisting in many ways in this study and Garry Wicks for helping with the language. Finally special thanks are due to Henrik Häll for his support and constructive comments.

\section{References}

[1] J. Von Schéele, M. Gartz, R. Paul, M. T. Lantz, J. P. Riegert, and S. Söderlund, "Flameless oxyfuel combustion for increased production and reduced $\mathrm{CO}_{2}$ and NOx emissions," Stahl und Eisen, vol. 128, no. 7, pp. 35-42, 2008.

[2] F. L. Horn and M. Steinberg, "Control of carbon dioxide emissions from a power plant (and use in enhanced oil recovery)," Fuel, vol. 61, no. 5, pp. 415-422, 1982.

[3] B. M. Abraham, J. G. Asbury, E. P. Lynch, and A. P. S. Teotia, "Coal-oxygen process provides $\mathrm{CO}_{2}$ for enhanced recovery," Oil Gas Journal, vol. 80, article 11, 1982.

[4] R. Tan, G. Corragio, and S. Santos, "Oxy-coal combustion with flue gas recycle for the power generation industry-a literature review," IFRF Doc. G 23/y/1, International Flame Research Foundation (IFRF), 2005.

[5] B. Golchert, P. Ridenour, W. Walker, M. Gu, N. K. Selvarasu, and C. Zhou, "Effect of nitrogen and oxygen concentrations on NOx emissions in an aluminum furnace," in Proceedings of the ASME 2006 International Mechanical Engineering Congress and Exposition, pp. 7918-4783, Chicago, Ill, USA, 2006.

[6] H. K. Kim, Y. Kim, S. M. Lee, and K. Y. Ahn, "NO reduction in 0.03-0.2 MW oxy-fuel combustor using flue gas recirculation technology," Proceedings of the Combustion Institute, vol. 31, pp. 3377-3384, 2007.

[7] K. Andersson, F. Normann, F. Johnsson, and B. Leckner, "NO emission during oxy-fuel combustion of lignite," Industrial and Engineering Chemistry Research, vol. 47, no. 6, pp. 1835-1845, 2008.

[8] F. Normann, K. Andersson, B. Leckner, and F. Johnsson, "Emission control of nitrogen oxides in the oxy-fuel process," Progress in Energy and Combustion Science, vol. 35, no. 5, pp. 385-397, 2009.

[9] M. B. Toftegaarda, J. Brixa, P. A. Jensena, P. Glarborga, and A. D. Jensena, "Oxy-fuel combustion of solid fuels," in Progress in Energy and Combustion Science, vol. 36, 2010.

[10] R. Johansson, K. Andersson, B. Leckner, and H. Thunman, "Models for gaseous radiative heat transfer applied to oxy-fuel conditions in boilers," International Journal of Heat and Mass Transfer, vol. 53, no. 1-3, pp. 220-230, 2010.

[11] C. Yin, "Nongray-gas effects in modeling of large-scale oxyfuel combustion processes," Energy and Fuels, vol. 26, no. 6, pp. 3349-3356, 2012.

[12] S. Hjärtstam, R. Johansson, K. Andersson, and F. Johnsson, "Computational fluid dynamics modeling of oxy-fuel flames: the role of soot and gas radiation," Energy and Fuels, vol. 26, no. 5, pp. 2786-2797, 2012.

[13] C. Yin, L. C. R. Johansen, L. A. Rosendahl, and S. K. Kær, "New weighted sum of gray gases model applicable to computational fluid dynamics (CFD) modeling of oxy-fuel combustion: derivation, validation, and implementation," Energy and Fuels, vol. 24 , no. 12, pp. 6275-6282, 2010. 
[14] P. Wang, F. Fan, and Q. Li, "Accuracy evaluation of the gray gas radiation model in CFD simulation," Case Studies in Thermal Engineering, vol. 3, pp. 51-58, 2014.

[15] R. Porter, F. Liu, M. Pourkashanian, A. Williams, and D. Smith, "Evaluation of solution methods for radiative heat transfer in gaseous oxy-fuel combustion environments," Journal of Quantitative Spectroscopy and Radiative Transfer, vol. 111, no. 14, pp. 2084-2094, 2010.

[16] A.-H. Wang, J.-J. Cai, and G.-W. Xie, "Numerical simulation of combustion characteristics in high temperature air combustion furnace," Journal of Iron and Steel Research International, vol. 16, no. 2, pp. 6-10, 2009.

[17] C. E. Baukal Jr., Oxygen-Enhanced Combustion, CRC Press, Boca Raton, Fla, USA, 2nd edition, 2013.

[18] P. Fredriksson, E. Claesson, P. Vesterberg, A. Lugnet, and O. Ritzen, Application of Oxyfuel Combustion in Reheating at Ovako, Hofors Works, Sweden-Background, Solutions and Results, S. l, Linde AGA, 2006.

[19] K. Narayanan, W. Wang, W. Blasiak, and T. Ekman, "Flameless oxyfuel combustion: technology, modeling and benefits in use," Revue de Métallurgie. Cahiers D'Informations Techniques, vol. 103, no. 5, pp. 210-217, 2006.

[20] N. Krishnamurthy, P. J. Paul, and W. Blasiak, "Studies on low-intensity oxy-fuel burner," Proceedings of the Combustion Institute, vol. 32, pp. 3139-3146, 2009.

[21] J. Chedaille and Y. Braud, Measurement in Flames, Hodder \& Stoughton Educ, 1972.

[22] J. A. Wünning and J. G. Wünning, "Flameless oxidation to reduce thermal no-formation," Progress in Energy and Combustion Science, vol. 23, no. 1, pp. 81-94, 1997.

[23] L. G. Blevins and W. M. Pitts, "Modeling of bare and aspirated thermocouples in compartment fires," Fire Safety Journal, vol. 33, no. 4, pp. 239-259, 1999.

[24] Fluent Theory Guide, ANSYS ${ }^{\circledR}$ Academic Research, Release 15, Help System, Non-premixed combustion, ANSYS, Inc.

[25] B. E. Launder and D. B. Spalding, "The numerical computation of turbulent flows," Computer Methods in Applied Mechanics and Engineering, vol. 3, no. 2, pp. 269-289, 1974.

[26] T.-H. Shih, W. W. Liou, A. Shabbir, Z. Yang, and J. Zhu, "A new $\mathrm{k}-\varepsilon$ eddy viscosity model for high reynolds number turbulent flows," Computers and Fluids, vol. 24, no. 3, pp. 227-238, 1995.

[27] Y.-S. Chen and S.-W. Kim, "Computation of turbulent flows using an extended k-epsilon turbulence closure model," NASA Report CR-179204, 1987.

[28] T. H. Shih, W. W. Liou, A. Shabbir, Z. Yang, and J. Zhu, "A new $k-\varepsilon$ Eddy viscosity model for high reynolds number turbulent flows-model development and validation," Document ID: 19950005029 (Acquired Dec 28, 1995) Accession Number: 95 N11442 Subject Category: FLUID Mechanics and Heat Transfer Report/Patent Number: NASA-TM-106721, ICOMP94-21, E-9087, NAS 1.15:106721, CMOTT-94-6 Document Type: Technical Report Publisher Information: United States, 1994, http://ntrs.nasa.gov/search.jsp?R=19950005029.

[29] W. Yang and W. Blasiak, "Numerical simulation of properties of a LPG flame with high-temperature air," International Journal of Thermal Sciences, vol. 44, no. 10, pp. 973-985, 2005.

[30] C. Yin, L. A. Rosendahl, and S. K. Kær, "Chemistry and radiation in oxy-fuel combustion: a computational fluid dynamics modeling study," Fuel, vol. 90, no. 7, pp. 2519-2529, 2011.

[31] M. Habermehl, J. Erfurth, D. Toporov, M. Förster, and R. Kneer, "Experimental and numerical investigations on a swirl oxycoal flame," Applied Thermal Engineering, vol. 49, pp. 161-169, 2012.
[32] M. Ghadamgahi, P. Ölund, A. Lugnet, M. Saffari Pour, and W. Yang, "Design optimization of flameless-oxyfuel soaking pit furnace using CFD technique," Energy Procedia, vol. 61, pp. 611614, 2014.

[33] M. F. Modest, Radiative Heat Transfer, Academic Press, 2013. 


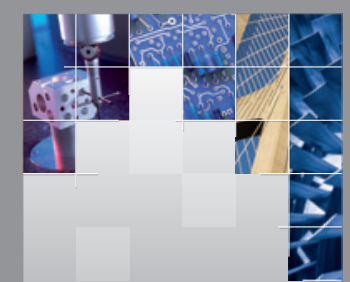

\section{Enfincering}
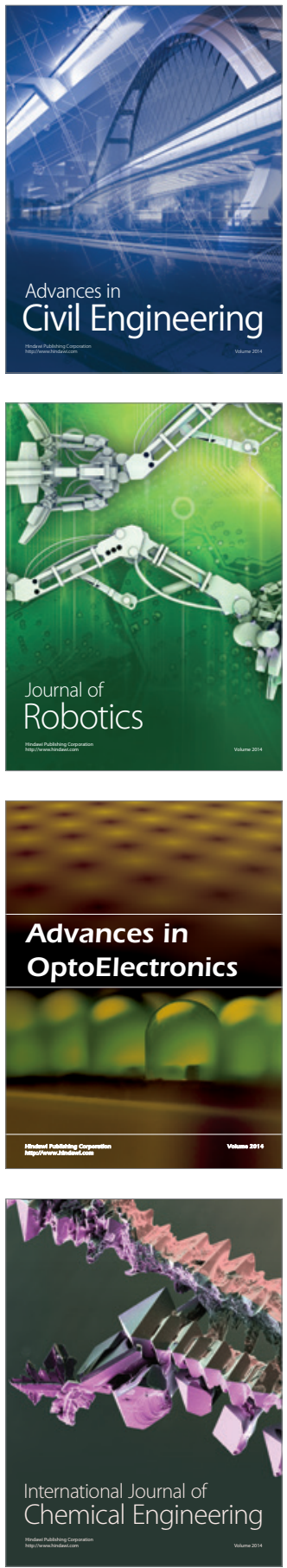

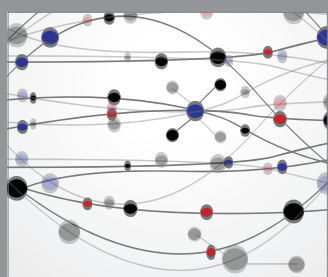

The Scientific World Journal

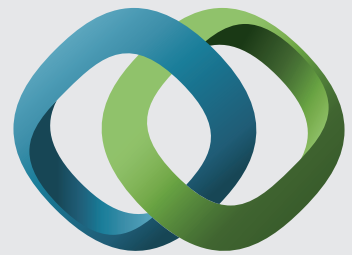

\section{Hindawi}

Submit your manuscripts at

http://www.hindawi.com
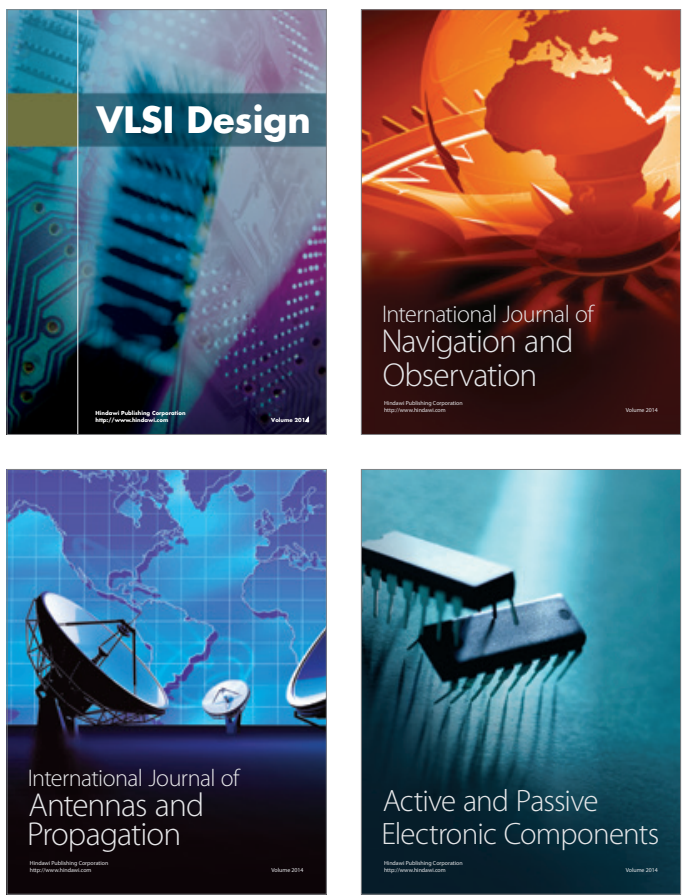
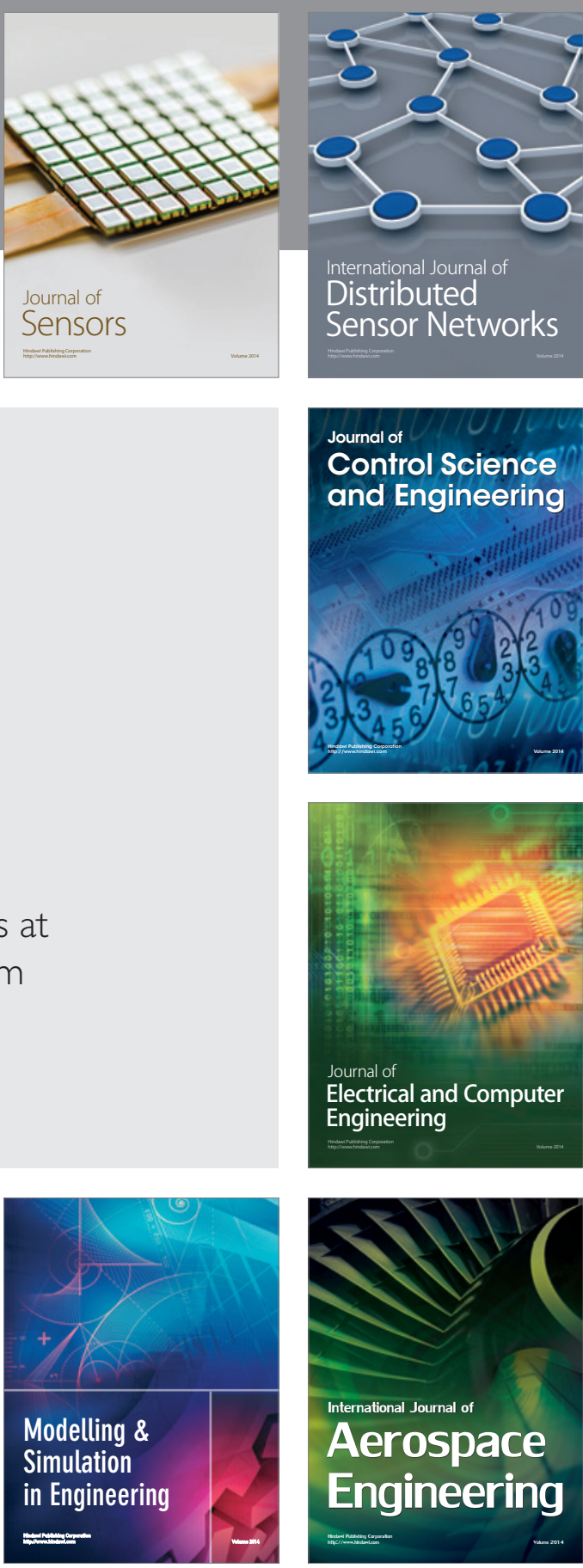

International Journal of

Distributed

Sensor Networks

Journal of

Control Science

and Engineering
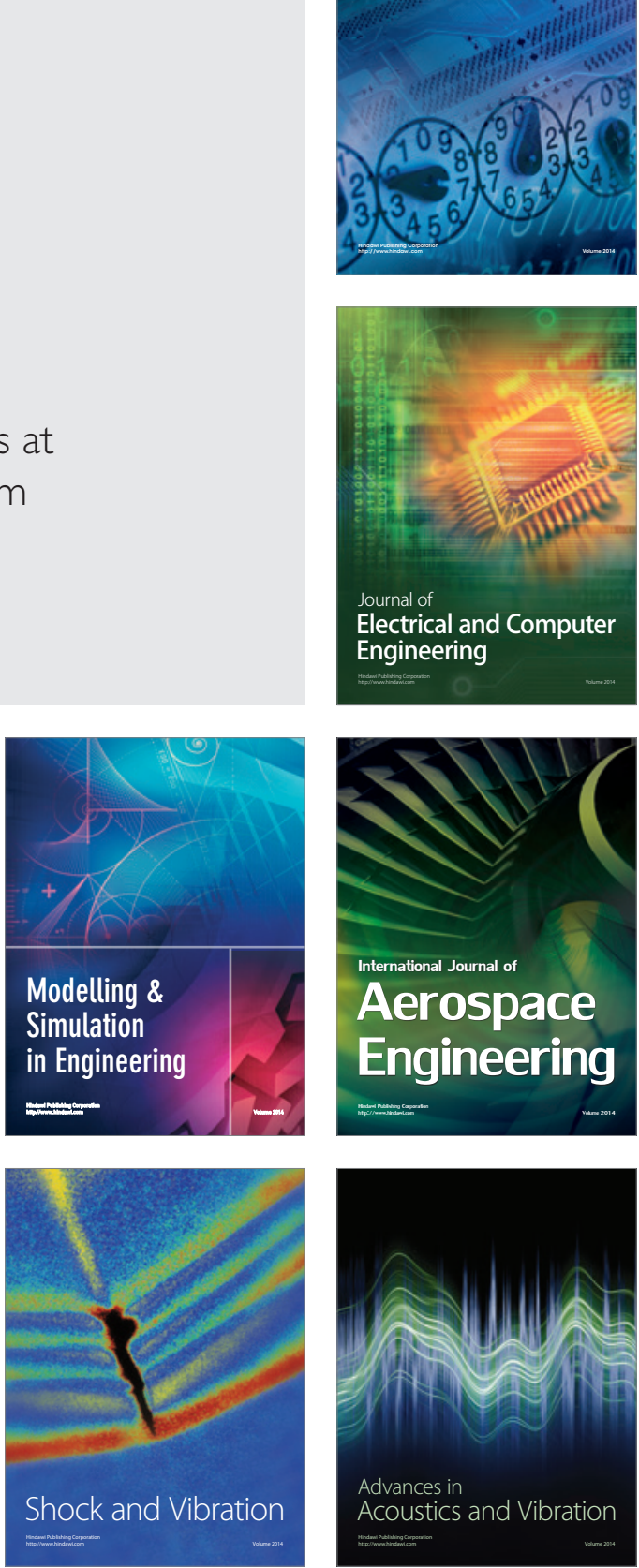